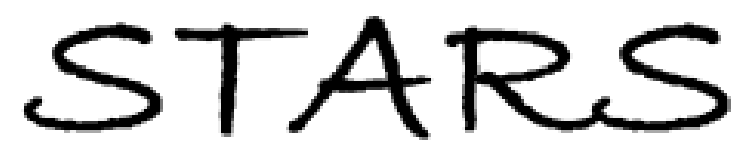

University of Central Florida

STARS

$1-1-2006$

\title{
Ultraviolet photoluminescence from 3C-SiC nanorods
}

Ligong Zhang

Weiyou Yang

Hua Jin

Zhuhong Zheng

Zhipeng Xie

See next page for additional authors

Find similar works at: https://stars.library.ucf.edu/facultybib2000

University of Central Florida Libraries http://library.ucf.edu

This Article is brought to you for free and open access by the Faculty Bibliography at STARS. It has been accepted for inclusion in Faculty Bibliography 2000 s by an authorized administrator of STARS. For more information, please contactSTARS@ucf.edu.

\section{Recommended Citation}

Zhang, Ligong; Yang, Weiyou; Jin, Hua; Zheng, Zhuhong; Xie, Zhipeng; Miao, Hezhuo; and An, Linan, "Ultraviolet photoluminescence from 3C-SiC nanorods" (2006). Faculty Bibliography 2000s. 6756. https://stars.library.ucf.edu/facultybib2000/6756

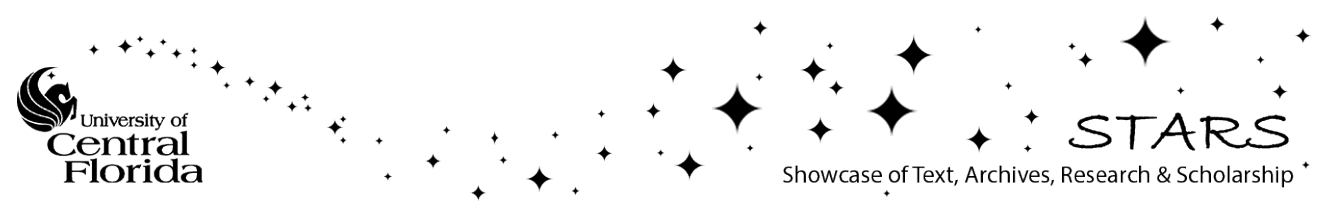




\section{Authors}

Ligong Zhang, Weiyou Yang, Hua Jin, Zhuhong Zheng, Zhipeng Xie, Hezhuo Miao, and Linan An 


\section{Ultraviolet photoluminescence from $3 C-\mathrm{SiC}$ nanorods}

Cite as: Appl. Phys. Lett. 89, 143101 (2006); https://doi.org/10.1063/1.2358313

Submitted: 18 March 2006 . Accepted: 14 August 2006 . Published Online: 02 October 2006

Ligong Zhang, Weiyou Yang, Hua Jin, Zhuhong Zheng, Zhipeng Xie, Hezhuo Miao, and Linan An

\section{ARTICLES YOU MAY BE INTERESTED IN}

Optical and electrical transport properties in silicon carbide nanowires

Applied Physics Letters 85, 1256 (2004); https://doi.org/10.1063/1.1781749

Fabrication of ZnS / SiC nanocables, SiC-shelled ZnS nanoribbons (and sheets), and SiC nanotubes (and tubes)

Applied Physics Letters 85, 2932 (2004); https://doi.org/10.1063/1.1801168

Fabrication and photoluminescence of SiC quantum dots stemming from $3 \mathrm{C}, 6 \mathrm{H}$, and $4 \mathrm{H}$ polytypes of bulk SiC

Applied Physics Letters 101, 131906 (2012); https://doi.org/10.1063/1.4755778

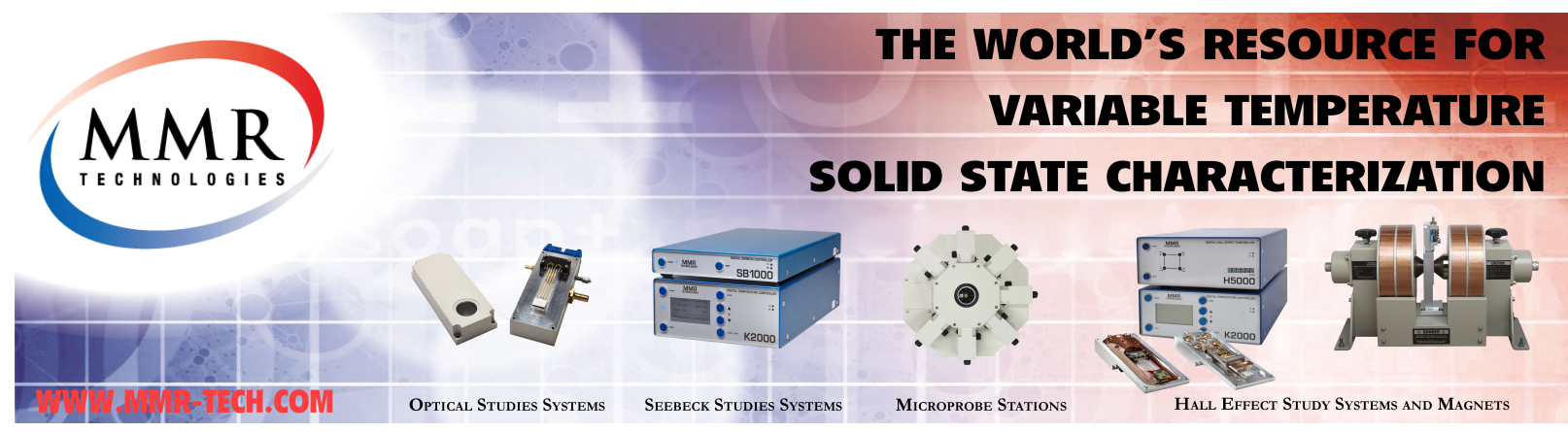




\title{
Ultraviolet photoluminescence from $3 C$-SiC nanorods
}

\author{
Ligong Zhang \\ Laboratory of Excited State Process, Changchun Institute of Optics, Fine Mechanics and Physics, \\ Chinese Academy of Sciences, Changchun 130032, People's Republic of China
}

Weiyou Yang

School of Mechanical Engineering, Ningbo University of Technology, Ningbo 315016, People's Republic of China

Hua Jin and Zhuhong Zheng

Laboratory of Excited State Process, Changchun Institute of Optics, Fine Mechanics and Physics, Chinese Academy of Sciences, Changchun 130032, People's Republic of China

Zhipeng Xie and Hezhuo Miao

State Key Lab of New Ceramics and Fine Processing, Tsinghua University, Beijing 100084, People's Republic of China

Linan $\mathrm{An}^{\mathrm{a}}$

Advanced Materials Processing and Analysis Center, University of Central Florida, Orlando, Florida 32816

(Received 18 March 2006; accepted 14 August 2006; published online 2 October 2006)

An intensive sharp photoluminescence at $3.3 \mathrm{eV}$ is observed from single-crystal $3 C$-SiC nanorods. Structural characterization reveals that the nanorods contain a fairly large amount of threefold stacking faults. We tentatively attribute the emission to these stalking faults, which structurally resemble $6 \mathrm{H}$-SiC nano-layers of $1.5 \mathrm{~nm}$ embedded in a $3 \mathrm{C}$-SiC matrix. The emission mechanism is discussed in terms of spontaneous polarization at the stacking faults. (c) 2006 American Institute of Physics. [DOI: 10.1063/1.2358313]

$\mathrm{SiC}$ is known for its wide-band-gap electronic structure as well as excellent thermal and mechanical properties, thus is potentially useful for applications in high-temperature electronics and short-wavelength optics. ${ }^{1} \mathrm{SiC}$ has been the leading material for high-temperature, high-power and highfrequency electronic devices due to advances in the crystal growth and doping ability for both $n$ and $p$ types. ${ }^{2}$ However, applications of $\mathrm{SiC}$ in optical devices are limited by its indirect band gap nature, which results in very low light emission efficiency. ${ }^{3}$ Increasing the light-emission efficiency for $\mathrm{SiC}$ has received considerable interest in the last two decades. Significant improvements have been made by using either porous or nano-sized systems. ${ }^{4-7}$ In these systems, the enhancements in light emission are mainly attributed to either surface defects or quantum confinement effects.

Improved luminescence has also been observed from $\mathrm{SiC}$ quantum well (QW) structures. ${ }^{8,9}$ The polytypism of $\mathrm{SiC}$ leads to a unique type of structure-only QW structures involving thin layers of cubic $3 C$-SiC (which has the smallest energy gap, $\sim 2.4 \mathrm{eV}$ ) embedded in higher energy gap $\mathrm{SiC}$ polytypes, such as $4 H$ - (energy gap $=3.3 \mathrm{eV}$ ) and $6 \mathrm{H}-\mathrm{SiC}$ (energy gap $=3.0 \mathrm{eV}) .{ }^{10}$ Because of the spontaneous polarization difference between cubic and hexagonal $\mathrm{SiC}$, internal electric fields are expected in the QW structures, which leads to the redshift of the luminescence peaks.

In this letter we report an intensive ultraviolet (UV) photoluminescence (PL) from threefold stacking faults in singlecrystal $3 \mathrm{C}$-SiC nanorods, which structurally resemble $6 \mathrm{H}$ $\mathrm{SiC}$ layers of $1.5 \mathrm{~nm}$ thickness embedded in a $3 C$-SiC matrix. In contrast to the aforementioned QW structures, quantum barrier structures should be formed in the current case

\footnotetext{
a) Author to whom correspondence should be addressed; electronic mail lan@mail.ucf.edu
}

since $6 \mathrm{H}$-SiC has a higher energy gap than $3 \mathrm{C}$-SiC.

The $\mathrm{SiC}$ nanorods used in this study were synthesized via catalyst-assistant crystallization of amorphous silicon carbonitride $(a-\mathrm{SiCN}) .{ }^{11}$ In brief, a polysilazane precursor was first decomposed to $a$-SiCN powder at $1000{ }^{\circ} \mathrm{C}$. The $a$-SiCN powder was then reacted with a catalyst $\left(\mathrm{FeCl}_{2}\right.$ in this study) to form $\mathrm{Si}-\mathrm{C}-\mathrm{Fe}$ liquid alloy droplets at temperatures higher than the tertiary eutectic point of the system. The nanorods were precipitated and grew from the liquid droplets at $1700{ }^{\circ} \mathrm{C}$ via a solid-liquid-solid mechanism. ${ }^{11}$ All heat treatments were performed in an ultrapure $\mathrm{N}_{2}$ atmosphere. The obtained nanorods are $80-200 \mathrm{~nm}$ in diameter and up to a few micrometers in length, and grown along [111] direction (Fig. 1).

The room-temperature steady-state PL spectrum of the nanorods was measured using a UV lamb micro-Raman

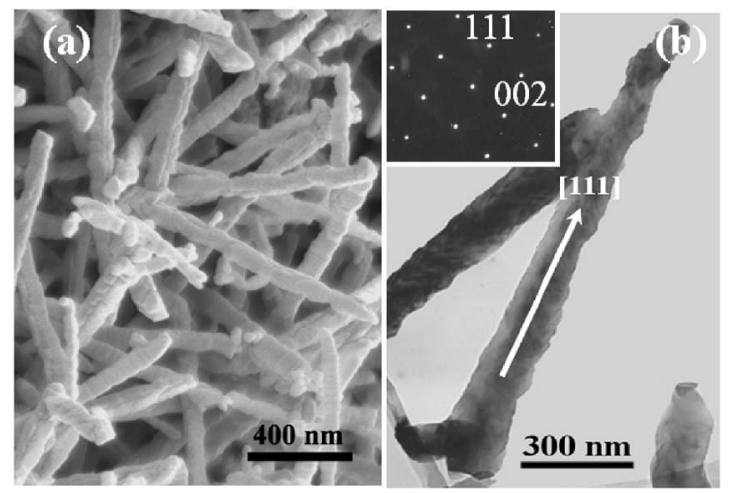

FIG. 1. (a) Scanning electron microscopy image showing the morphology of the $\mathrm{SiC}$ nanorods. (b) TEM image of an individual nanorod. The inset is the corresponding electron diffraction pattern, showing that the nanorod grows along [111] direction. 


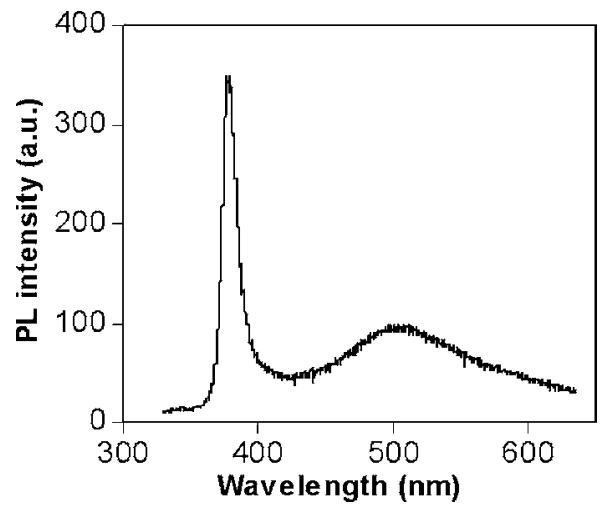

FIG. 2. Room-temperature steady-state PL spectrum of the SiC nanorods.

spectrometer with a $\mathrm{He}-\mathrm{Cd}$ laser of $325 \mathrm{~nm}$ wavelength and $5 \mathrm{~mW}$ output power as the excitation light source. The spectrum (Fig. 2) reveals two emission peaks: a strong, sharp UV emission at $378 \mathrm{~nm}(3.3 \mathrm{eV})$ and a broad, green emission ranging from 450 to $600 \mathrm{~nm}$. The intensity of the UV emission is more than five times higher than that of the green emission. While the broad emission between 450 and $600 \mathrm{~nm}$ might be attributed to $3 C-\mathrm{SiC}^{7,12}$ the strong emission at $3.3 \mathrm{eV}$, which is significantly higher than the band gap of crystalline $3 C$-SiC, is difficult to explain and has never been observed in $3 C$-SiC previously. The UV emission cannot be attributed to structural defects in $\mathrm{SiC}$, such as dislocations, carbon di-interstitial, di-vacancies or isolated vacancies at the Si site, because the PL signals resulting from these defects are in the unique range of $1.9-2.3 \mathrm{eV} .{ }^{13,14}$ The $\mathrm{UV}$ emission is also different from that observed in porous or nano-sized $3 C$-SiC, where PL signals associated with either quantum confinement or surface defects are generally below $2.8 \mathrm{eV}^{4-6}$ In addition, the dimensions of the nanorods are too large to have significant quantum confinement effects. A $3.26 \mathrm{eV}$ PL peak has been frequently observed in crystalline silicon dioxide films and was attributed to oxygen vacancies. ${ }^{15-17}$ However, this cannot explain the current results since no such oxide films were observed on the surface of the nanorods. The absence of an oxide film is due to the fact that the nanorods were synthesized in an ultrapure $\mathrm{N}_{2}$ environment.

In order to understand the origin of the UV emission, the structure of the $\mathrm{SiC}$ nanorods was characterized using highresolution transmission electron microscopy (HRTEM). Figure 3(a) is a typical HRTEM image of the nanorods, showing that the nanorods contain a fairly high concentration of stacking faults, which are perpendicular to [111], growth direction [Fig. 1(b)]. This result is consistent with X-ray diffraction (XRD) pattern that revealed a large amount of stacking faults in the $\mathrm{SiC}$ nanorods [Fig. 3(b)]. Detailed observation at higher magnification [inset in Fig. 3(a)] reveals that the stacking faults are threefold in nature (three immediately adjacent single stacking faults). It should be noted that the region around the threefold stacking faults resembles the structure of $6 \mathrm{H}$-SiC [Fig. 3(c)]. Therefore, the structure of the nanorods can be viewed as a $3 \mathrm{C}-\mathrm{SiC}$ matrix containing $6 \mathrm{H}$-SiC-like nano-scaled layers. According to this model, the thickness of these $6 H$-SiC-like layers should be about the length of the $c$ axis of $6 \mathrm{H}$-SiC unit cell, which is $\sim 1.5 \mathrm{~nm}$. Such thin layers cannot be detected by XRD since the formation of XRD peaks requires at least several unit


FIG. 3. (a) Raman spectrum of the nanorods. The red line is the experimental result and the blue line is the curve fit by addition of the pink lines. (b) XRD pattern showing that the nanorods are pure $3 C$-SiC containing stacking faults. (c) HRTEM image showing the stacking faults in the nanorods. The inset is the enlargement of the selected area revealing the threefold stacking fault nature. (d) Schematic model of perfect $3 C$-SiC and $3 C$-SiC containing a threefold stacking fault; the region around the stacking fault (between two dash lines) shows the structure resembling that of $6 \mathrm{H}$-SiC.

cells. Thus XRD pattern showed only $3 C$-SiC peaks [Fig. 3(b)].

Based on the above discussion, we tentatively attribute the intensive light emission at $3.3 \mathrm{eV}$ to the unique structure of the $\mathrm{SiC}$ nanorods. According to Qteish, Heine, and Needs, in $\mathrm{SiC}$ a spontaneous polarization takes place around each hexagonal turn, ${ }^{18}$ which is quite strongly localized at the turn. Such spontaneous polarization leads to electric dipole moments being built in throughout the $6 H$-SiC nano-layers. These electric dipoles can cause opposite charges on both sides of the nano-layers. ${ }^{19}$ These localized charges can lead to potential barriers in the conduction band at the boundaries of the $6 \mathrm{H}$-SiC nano-layers. ${ }^{18}$ The barriers will constrict elec- 


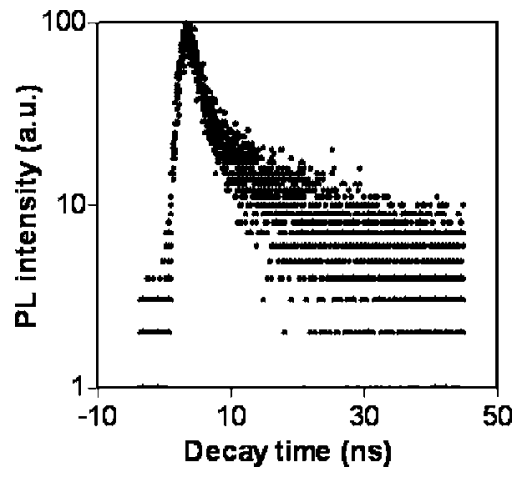

FIG. 4. Room-temperature time evolution of the luminescence intensity of the emission at $3.3 \mathrm{eV}$.

trons within $6 \mathrm{H}$-SiC layer and thus electronically isolate the layers from the $3 \mathrm{C}-\mathrm{SiC}$ matrix. Consequently, the $6 \mathrm{H}-\mathrm{SiC}$ layers may act as free-standard nano-sized sheets of $1.5 \mathrm{~nm}$ in thickness, which should lead to strong blueshifted light emission $(3.3 \mathrm{eV}$ is higher than the band gap of bulk $6 \mathrm{H}$ $-\mathrm{SiC})$ due to a quantum confinement effect. It is instructive to note that the position and shape of the $3.3 \mathrm{eV}$ emission observed from the nanorods closely resembles that of the PL peak theoretically predicted for $1.5 \mathrm{~nm} 6 \mathrm{H}$-SiC clusters. ${ }^{20}$

Further characterization of the PL behavior of the nanorods was carried out by measuring their room-temperature time-resolved PL spectrum using a fluorescence lifetime spectrometer with a resolution of $100 \mathrm{ps}$. Figure 4 shows the time evolution of the luminescence intensity of the emission at $3.3 \mathrm{eV}$. The best fit to the curve was obtained using a biexponential decay process. The biexponential decay implies that multi levels may be involved in the radiative recombination. Two decay time constants of 1.0 and $6.5 \mathrm{~ns}$ were obtained. It should be noted that the decay times of around $1 \mathrm{~ns}$ are at least two orders of magnitude shorter than that for bulk SiC. ${ }^{21}$ Such short decay times were typically observed for the emission from nano-structured indirectband-gap materials. ${ }^{22,23}$

In summary, we report an intensive sharp UV emission from single-crystal $3 C$-SiC nanorods grown via catalystassisted pyrolysis of a polymeric precursor. We attribute this unique emission to the threefold stacking faults in the $3 C$-SiC matrix. The nanorods, which could possibly be assembled into nanostructures capable of emitting strong ultraviolet light, would be useful for short wavelength nanodevices.

${ }^{1}$ H. Morkoc, S. Strite, G. B. Gao, M. E. Lin, B. Sverdlov, and M. Burns, Appl. Phys. A 76, 1363 (1994).

${ }^{2}$ J. A. Powell, P. G. Neudeck, L. G. Matus, and J. B. Petit, in Wide Bandgap Semiconductors, edited by T. D. Moustakas, J. I. Pankove, and Y. Hamakawa (Material Research Society, Pittsburgh, PA, 1992), Proc. 242, p. 495.

${ }^{3}$ L. Hoffman, G. Ziegler, D. Theis, and C. Weyrich, J. Appl. Phys. 53, 6962 (1982).

${ }^{4}$ L. S. Liao, X. M. Bao, Z. F. Yang, and N. B. Min, Appl. Phys. Lett. 66, 2382 (1995).

${ }^{5}$ M. Yu, Rusli, S. Yoon, S. Xu, K. Chew, J. Cui, J. Ahn, and Q. Zhang, Thin Solid Films 377-378, 177 (2000).

${ }^{6}$ D. Chen, Z. Liao, L. Wang, H. Wang, F. Zhao, W. Cheung, and P. Wong, Opt. Mater. (Amsterdam, Neth.) 23, 65 (2003).

${ }^{7}$ X. Wu, J. Fan, T. Qiu, X. Yang, G. Siu, and P. Chu, Phys. Rev. Lett. 94, $026102(2005)$

${ }^{8}$ S. Bai, R. P. Devaty, W. J. Choyke, U. Kaiser, G. Wagner, and M. F. MacMillan, Appl. Phys. Lett. 83, 3171 (2003).

${ }^{9}$ R. S. Okojie, M. Zhang, P. Pirouz, S. Tumakha, G. Jessen, and L. J. Brillson, Appl. Phys. Lett. 79, 3056 (2001).

${ }^{10}$ A. Fissel, U. Kaiser, B. Schröter, W. Richter, and F. Bechstedt, Appl. Surf. Sci. 184, 37 (2001).

${ }^{11}$ W. Yang, Z. Xie, H. Miao, L. Zhang, and L. An, Chem. Phys. Lett. 383, 441 (2004).

${ }^{12}$ X. Wu, G. Siu, M. J. Stokes, D. Fan, Y. Gu, and X. Bao, Appl. Phys. Lett. 77, $1292(2000)$.

${ }^{13}$ W. J. Choyke, Z. Feng, and J. A. Powell, J. Appl. Phys. 64, 3163 (1988).

${ }^{14}$ H. Itoh, M. Yoshikawa, I. Nashiyama, H. Okumura, S. Misawa, and S. Yoshida, J. Appl. Phys. 77, 837 (1995).

${ }^{15}$ H. Song, X. Bao, N. Li, and X. Wu, Appl. Phys. Lett. 72, 356 (1998).

${ }^{16}$ K. Kim, M. S. Suh, T. S. Kim, C. J. Youn, E. K. Suh, Y. J. Shin, K. B. Lee, and H. J. Lee, Appl. Phys. Lett. 69, 3908 (1996).

${ }^{17}$ G. Siu, X. Wu, Y. Gu, and X. Bao, Appl. Phys. Lett. 74, 1812 (1999).

${ }^{18}$ A. Qteish, V. Heine, and R. J. Needs, Phys. Rev. B 45, 6534 (1992).

${ }^{19}$ H. P. Iwata, U. Lindefelt, S. Öberg, and P. R. Briddon, Physica B 340342, 165 (2003).

${ }^{20}$ A. Kassiba, M. Makowska-Janusik, J. Bouclé, J. F. Bardeau, A. Bulou, and N. Herlin-Boime, Phys. Rev. B 66, 155317 (2002).

${ }^{21}$ S. G. Bishop and J. A. Freitas, Jr., J. Cryst. Growth 106, 38 (1990).

${ }^{22}$ S. J. Xu, M. B. Yu, Rusli, S. F. Yoon, and C. M. Che, Appl. Phys. Lett. 76, 2550 (2000).

${ }^{23}$ J. P. Wilcoxon and G. A. Samara, Appl. Phys. Lett. 74, 3164 (1999). 